\title{
Removal of Reactive Red 1 dye from aqueous solution using gypsum
}

\author{
C. C. OBUNWO ${ }^{1 *}$, I. UBONG ${ }^{2}$ and G. I. ORDU ${ }^{1}$ \\ ${ }^{I}$ Department of Chemistry, University of Science and Technology, Rivers State, Port Harcourt, Nigeria. \\ ${ }^{2}$ Institute of Pollution Studies, University of Science and Technology, Rivers State, Port Harcourt, \\ Nigeria. \\ *Corresponding author, E-mail: ccobunwo@yahoo.com
}

\begin{abstract}
In order to establish the capacity of gypsum in the removal of dyes from aqueous solutions, the adsorption behaviour of Reactive Red 1 (RR1) from aqueous solution onto gypsum was investigated under several different operating parameters namely, contact time, adsorbent dosage, $\mathrm{pH}$, particle size, and adsorbate dosage, at ambient temperature. The study employed the batch experiment method and utilized two different particle sizes $(150 \mu \mathrm{m}$ and $300 \mu \mathrm{m})$ of the adsorbent. Two portions of each particle size were subjected to two different treatments (acid and base) while a third portion remained untreated. Acidic medium favoured the dye removal at an optimal $\mathrm{pH}$ of 2 and an optimal contact time of 25-35 minutes. Optimal adsorption was also recorded at an adsorbent dosage of $0.8 \mathrm{~g}$. Under optimal conditions, $89.8 \%$ adsorption was recorded with the $150 \mu \mathrm{m}$ particle size of the adsorbent in the acid-treated medium. Both Langmuir and Freundlich isotherms could be used to describe adsorption of the dye, with the value of the separation factor of the Langmuir isotherm (RL) lying well in between 0 and 1 . The Freundlich isotherm intensity parameter $(1 / \mathrm{n})$ also fell in between 0 and 1 - indicating that both isotherm processes are favourable. The experimental data fitted well to the pseudo-second-order kinetics model with R2>0.99 indicating that chemisorption was the rate-controlling step in the adsorption of the dye. The smaller particle size $(150 \mu \mathrm{m})$ adsorbed higher amount of the dye because of its larger surface area. Acid treated adsorbents yielded higher dye removal than the untreated and the base treated

(C) 2012 International Formulae Group. All rights reserved.
\end{abstract}

Keywords: Reactive Red 1 dye; Adsorption; Isotherms; Kinetics; Gypsum.

\section{INTRODUCTION}

The use of dyes by textile, paper, plastic, food and pharmaceutical industries to colour their products is a common occurrence. These industries use substantial amounts of water in their processes- resulting in the discharge of highly coloured effluents (Suteu et al., 2010). The discharge of these untreated coloured effluents into water bodies is currently a major problem for environmental management especially in developing countries. Coloured substances in water bodies tend to reduce sunlight penetration which is essential for many photo-initiated chemical reactions necessary for aquatic life, thus affecting the growth of plants and impacting on invertebrates and other forms of wildlife (Crini, 2006). Furthermore, effluents containing dyes are difficult to treat because most of these chemicals are not prone to aerobic digestion (Alaton et al., 2008). Increased environmental awareness as well as environmental regulations on the organic content of industrial effluents makes it necessary to eliminate dyes from wastewater before they are discharged into water bodies. 
Although, there are several methods for the removal of pollutants from effluents, there is no single process capable of treating these effluents (Ghoreishi and Haghighi, 2003). Practically, a combination of different processes is often used to achieve the desired water quality in the most economical way. Liquid-phase adsorption is one of the most studied methods in the removal of pollutants from wastewater (Al-Asheh et al., 2003; Khraisheh and Alg-Houti 2005; Cestari et al., 2008). The treatment of wastewaters by adsorption process is an excellent choice especially if the adsorbent is inexpensive and does not require any additional pre-treatment step before its application. The main adsorbents used to remove dyes in wastewater employs activated carbon because of its good adsorption ability (Tan et al., 2007; Iqbal and Ashiq, 2007). The use of activated carbon, however, is restricted due to its high cost. An attempt to develop cheaper, effective and nonconventional low-cost adsorbents such as clay, zeolites, agricultural and industrial waste products have also been suggested (Crini, 2006; Lehocky and Mracek, 2006; Bakaullah et al., 2007). This study is aimed at exploring the use of the commonly available commodity, gypsum in treating industrial effluents. It is a hydrated salt of Calcium Sulphate $\left(\mathrm{CaSO}_{4} .2 \mathrm{H}_{2} \mathrm{O}\right)$ abundantly found in sedimentary environments of high saline water. It is cheap to obtain and requires no pre-treatment compared with activated coal (Isa et al., 2007; Rauf et al., 2009). In this study, attention is focused on the use of gypsum as an adsorbent in the removal of Reactive Red 1 dye (RR 1) from aqueous solutions. Reactive Red 1 dye ((32) - 5 - [4.6 - diamino - 1, 3, 5 - triazin - 2yl) amino] - 4 - oxo - 3 - [(2 - sulfopheyl $)$ hydrazinylidene $]$ naphthalene 2, 7 - dissulfonic acid) has been reported to be employed in both textile and printing industries (Karstens and Kobs, 1980; Kubin and Fletcher, 1982). This dye, on discharge into water bodies, releases aromatic amines - a potential carcinogen (Boeningo,
1994). In Port Harcourt city, Nigeria, printing and plastic industries abound-arising from the commercial and industrial setting of the city. The city is criss-crossed with a number of streams which serve as a natural drainage system. Effluents and wastes from these industries are indiscriminately discharged into the streams. Rauf et al. (2009) in a study had demonstrated the potentiality of gypsum to remove methylene blue dye from aqueous solution. It is hoped that gypsum will also efficiently remove Reactive Red 1 dye from aqueous solution.

\section{MATERIALS AND METHODS}

The gypsum powder was sieved into $150 \mu \mathrm{m}$ and $300 \mu \mathrm{m}$ particle sizes. Each particle size was divided into three portions; two of which were subjected to acid and base treatments respectively for 48 hours. The third portion was kept unmodified. Each portion was filtered and dried in a desiccator. Serial dilutions of the stock solution of the RR-1 dye $\left(100 \mathrm{mg} / \mathrm{dm}^{3}\right)$ were used to perform at ambient temperature the various batch adsorption processes involving the determination of optimal contact time and $\mathrm{pH}$ as well as maximum adsorbate and adsorbent dosages (Obunwo and Akassawei, 2011). Optimal contact time was determined by measuring into each sample bottle, $0.3 \mathrm{~g}$ of the powder (of a particle size) and $20 \mathrm{ml}$ of a known concentration of the RR-1 dye stock solution. The mixture was shaken in a mechanical shaker at $600 \mathrm{rpm}$. Two sample flasks were withdrawn from the shaker at predetermined time intervals of 30 minutes for a period of 180 minutes. The mixture in each of the flasks was filtered and the filtrate centrifuged at the speed of $2800 \mathrm{rpm}$ for 5 minutes. The supernatant was decanted and the residual amount was determined using the ultraviolet-visible spectrophotometer. Optimal $\mathrm{pH}$ was also determined by measuring $20 \mathrm{ml}$ of the stock solution and adjusted to a desired $\mathrm{pH}$ value with either $0,1 \mathrm{M} \mathrm{NaOH}$ or $0.1 \mathrm{M}$ $\mathrm{HCl}$ solution. A mixture of the solution and 
the powder was then shaken in the mechanical shaker followed by centrifuging. Different concentrations of the dye, ranging from 0.008 to $0.020 \mathrm{mg} / \mathrm{l}$ were each mixed to $0.3 \mathrm{~g}$ of the adsorbent. The mixture was shaken followed by centrifuging. Optimal contact time and $\mathrm{pH}$ were maintained. Into different sample flasks, adsorbent dosages ranging between $0.2 \mathrm{~g}$ and $1.2 \mathrm{~g}$ were each mixed with $20 \mathrm{mls}$ of the dye solution. The mixture was shaken followed by centrifuging. Optimal contact time and $\mathrm{pH}$ were maintained.

\section{RESULTS AND DISCUSSION}

The influence of particle size on the adsorption of reactive red 1 (RR1) dye onto gypsum was studied with two different particle sizes: $300 \mu \mathrm{m}$ and $150 \mu \mathrm{m}$. The results (Figure 1) show that the smaller particle size, $150 \mu \mathrm{m}$, yielded higher adsorption. This trend may be attributed to the larger surface area of the $150 \mu \mathrm{m}$ adsorbent. Studies by Nethaji et al. (2010) on the adsorption of malachite green dye onto activated carbon derived from Borassus aethiopum flower biomass reported that smaller particles created larger surface areas than bigger particles. The effect of chemical pre-treatment on the adsorption of Reactive Red 1 (RR1) dye onto Gypsum was in the order acid-treated > untreated base-treated. Irrespective of the particle size, this order was maintained. Martin et al. (2003) in their studies on the efficiency of chemically treated adsorbents to remove dyes from aqueous solution onto activated carbon confirmed that adsorbents treated or obtained in the presence of sulphuric acid possessed relatively high adsorption capacity for aqueous dyes of large molecular weight; those treated with base decreased adsorption due to negatively charged activated carbon. Other studies on chemical treatment of adsorbents (Inthorn et al., 2004; Gong et al., 2005 and Ncibi et al., 2007) have also shown that acid- treated biomass yielded higher adsorption. Optimal contact time was attained within the range of
25 - 35 mins (Figure 2) with both particle sizes of the adsorbent. This trend is in agreement with studies by Rauf et al. (2009) on the removal of methylene blue from aqueous solution by using gypsum. The optimal contact time was reported to be in the range of $20-40$ mins. In terms of the effect of $\mathrm{pH}$, the optimal $\mathrm{pH}$ was recorded at $\mathrm{pH} 2$ (Figure 3) with both particle sizes of the adsorbent. The uptake of the dye decreased with increase in $\mathrm{pH}$. An acidic medium may thus enhance the adsorption of the dye. Isa et al. (2006) had reported that positive charges which dominate the surface of the gypsum adsorbent tend to promote adsorption in the acidic medium. In varying the adsorbent dosage, optimal adsorption was recorded with $0.8 \mathrm{~g}$ of the adsorbent at the different particle sizes. However, the maximum percentage adsorption of $89.8 \%$ was recorded with the $150 \mu \mathrm{m}$ particle size adsorbent in the acidtreated medium (Figure 4). For the known amount of the adsorbent $(0.30 \mathrm{~g})$, adsorption increased with increase in the adsorbate dosage (Figure 5). However, an optimal adsorbate dosage was not attained presumably as a result of the range of concentration of the adsorbate $(0.008-0.02 \mathrm{mg} / \mathrm{l})$. The kinetics of the adsorption processes with both particle sizes showed that the pseudo-second order fitted better than the pseudo-first order in the different treatments $(\mathrm{R} 2 \geq 0.9)$ - Figures 6 and 7. It is thus suggested that the rate-controlling step might be a process of chemisorption (Ozacar and Sengel, 2003; Chiou and Li, 2003). By the application of Langmuir and Freundlich isotherm model equations for the two particle sizes, the results of the adsorption isotherm indicated that both Langmuir and Freundlich models fitted well $\left(\mathrm{R}^{2}>0.98\right)$ (Figures 8 and 9). The Langmuir Isotherm separation factor $R_{L}$ fell in the range of 0-1 in all cases, which clearly showed that the adsorption process was favourable. Freundlich Isotherm model also proved that the adsorption was favourable with $1 / \mathrm{n}<1$ in all cases. 

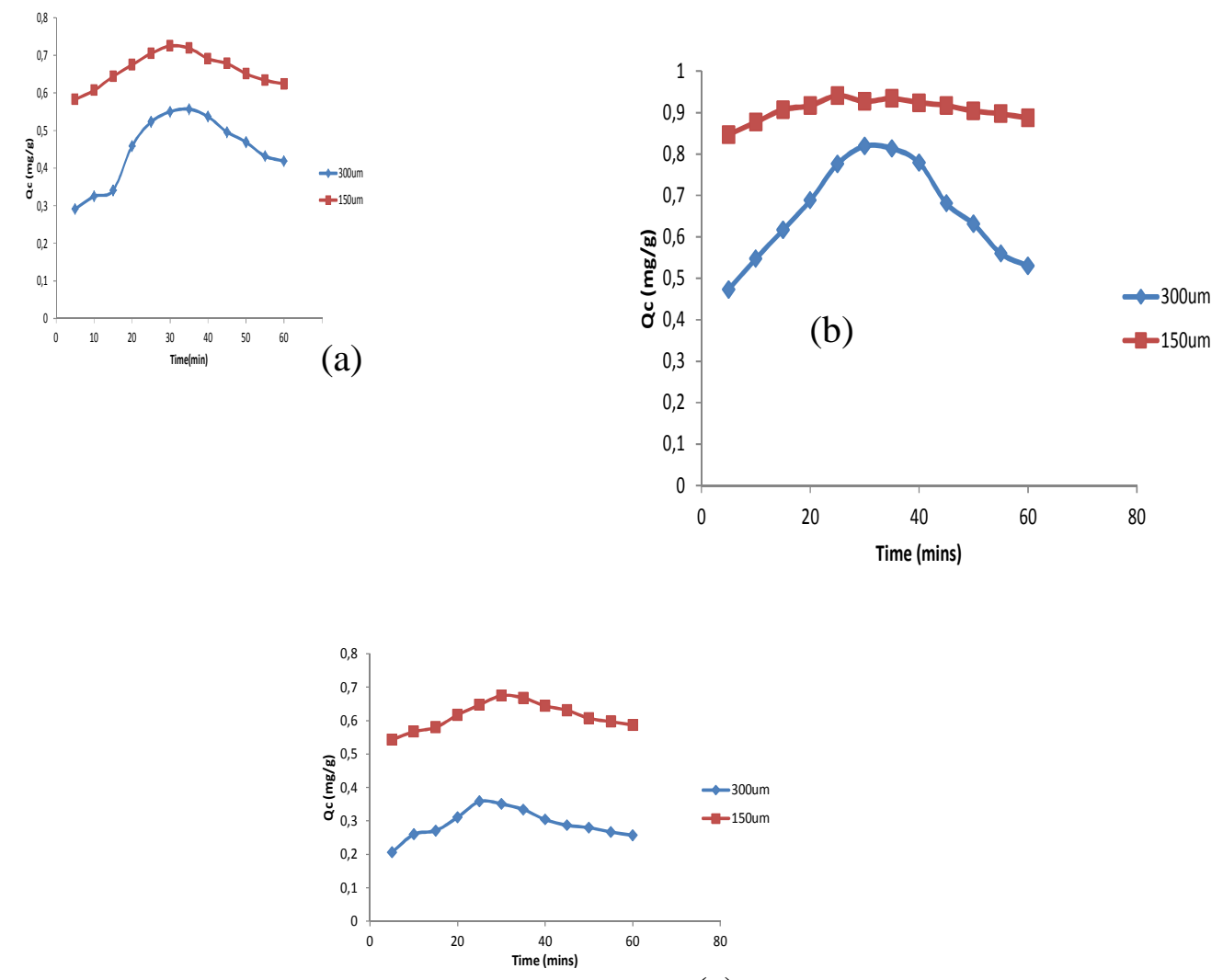

(c)

Figure 1: A comparison of adsorption with different particle sizes (a) untreated; (b) Acid-treated; (c) base-treated Gypsum.

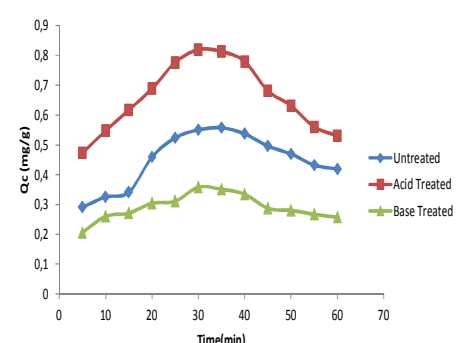

(a)

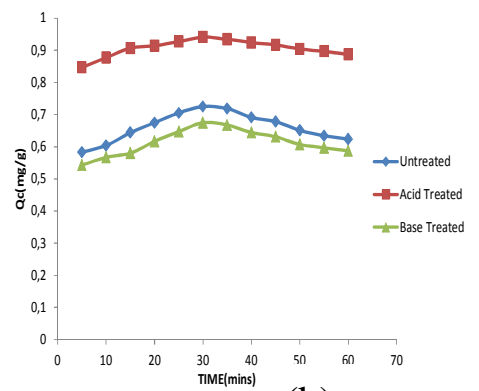

(b)

Figure 2: Plot of adsorption capacity against contact time (a) $300 \mu \mathrm{m}$; (b) $150 \mu \mathrm{m}$ gypsum. 

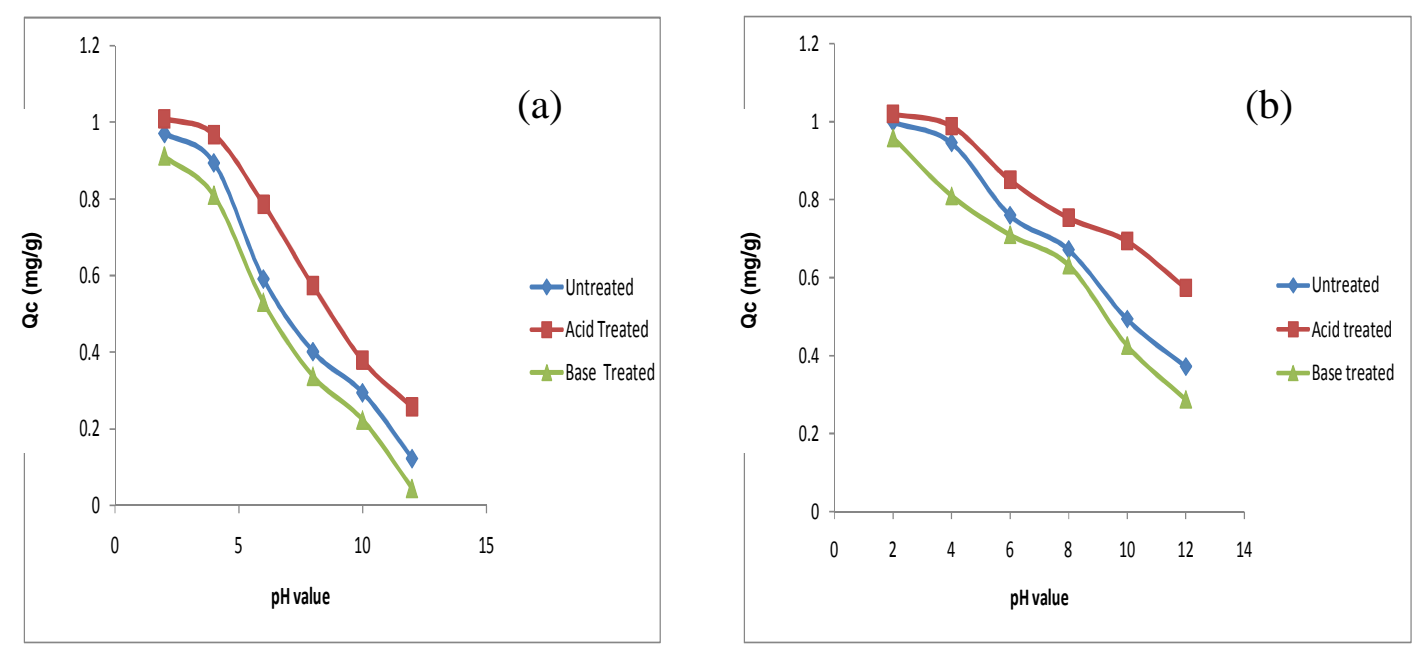

Figure 3: Plot of adsorption capacity against $\mathrm{pH}$ (a) $300 \mu \mathrm{m}$; (b) $150 \mu \mathrm{m}$ gypsum.
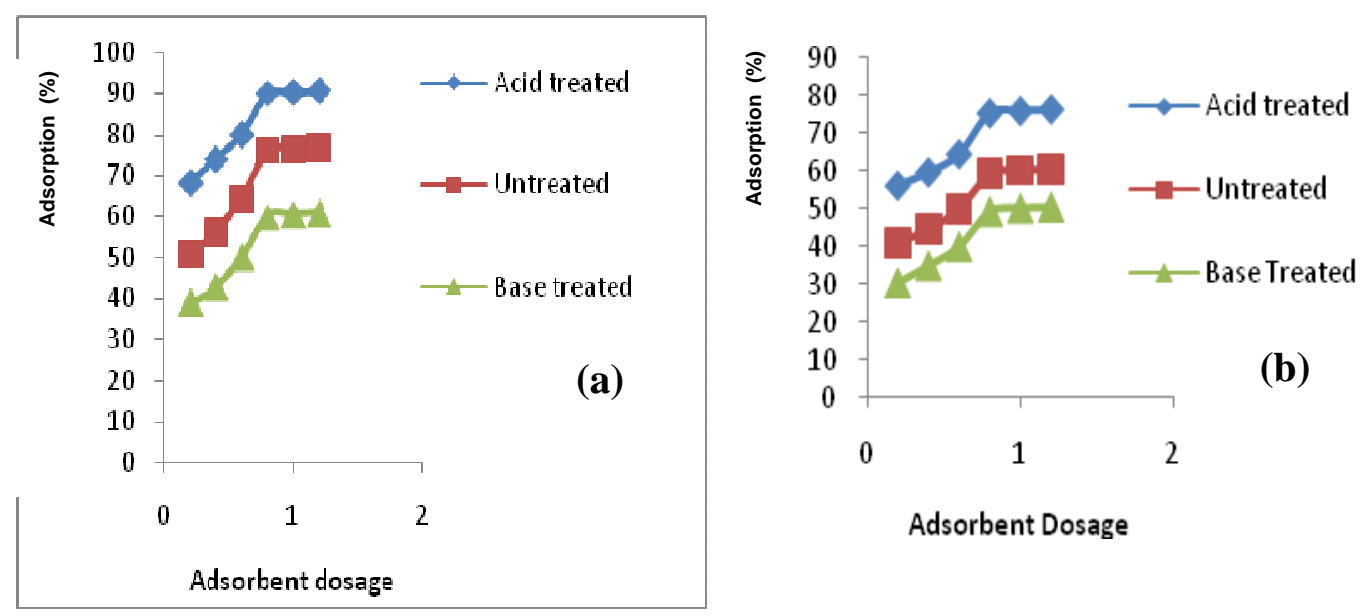

Figure 4: Plot of adsorption capacity against adsorbent dosage (a) $300 \mu \mathrm{m}$; (b) $150 \mu \mathrm{m}$ gypsum. 

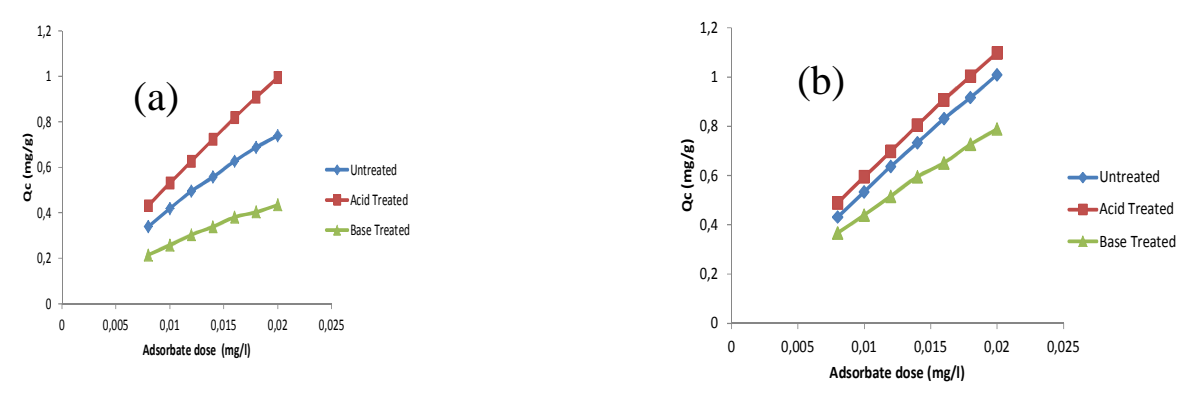

Figure 5: Plot of adsorption capacity against adsorbate dosage (a) $300 \mu \mathrm{m}$; (b) $150 \mu \mathrm{m}$ gypsum.
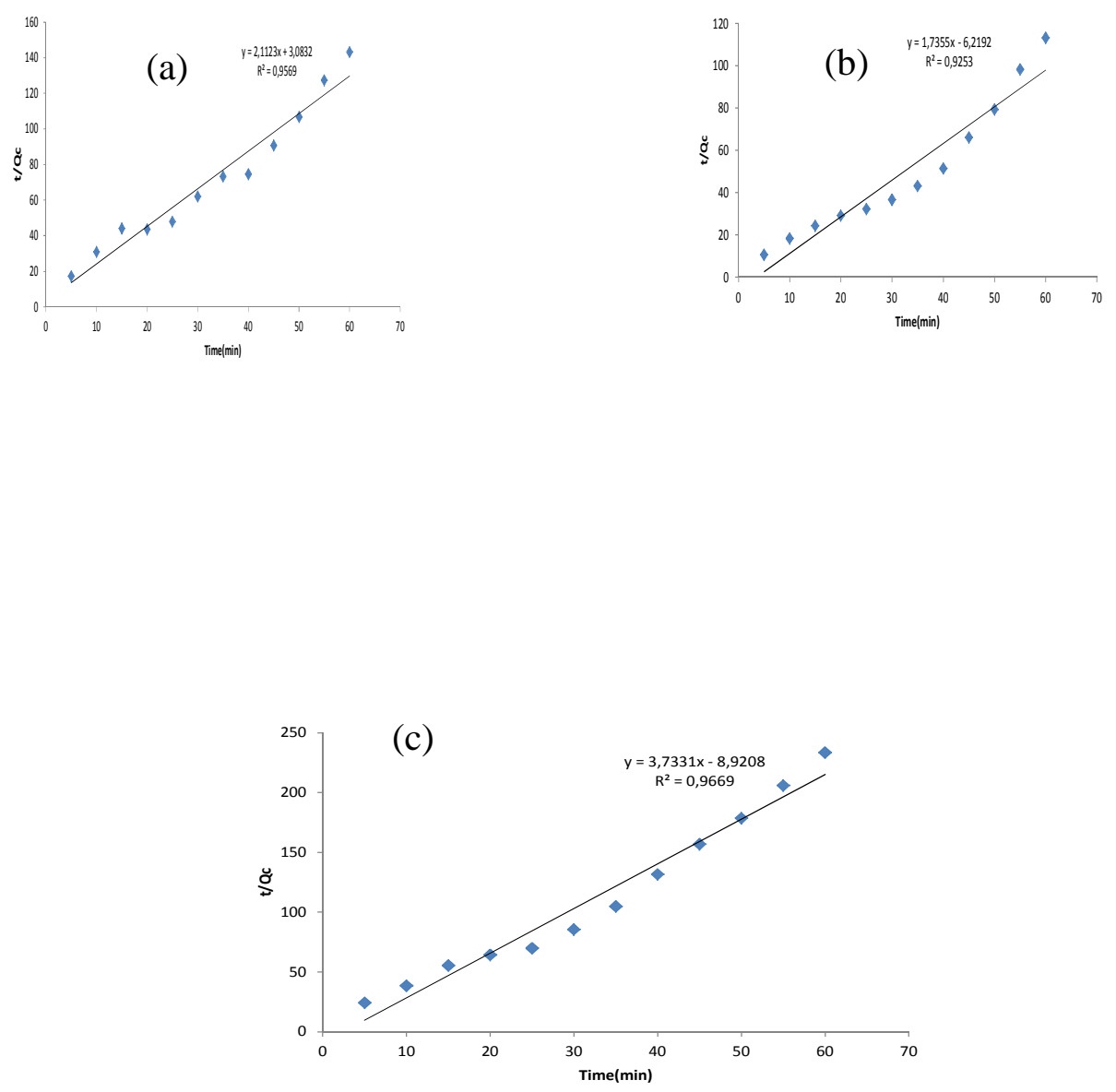

Figure 6: Pseudo-Second-order with (a) untreated; (b) acid-treated and (c) base- treated $300 \mu \mathrm{m}$ Gypsum. 
(a)

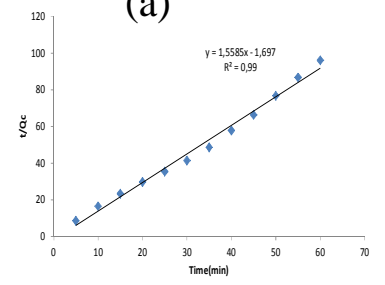

(b)

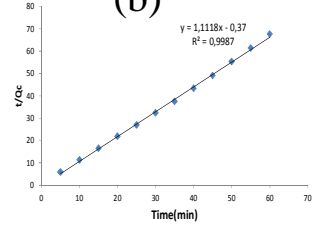

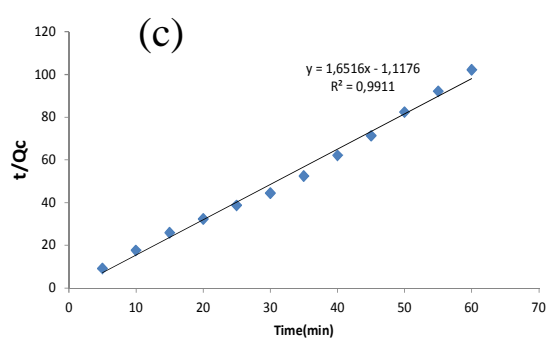

Figure 7: Pseudo-Second-order with (a) untreated; (b) acid-treated and (c) base- treated $150 \mu \mathrm{m}$ Gypsum.
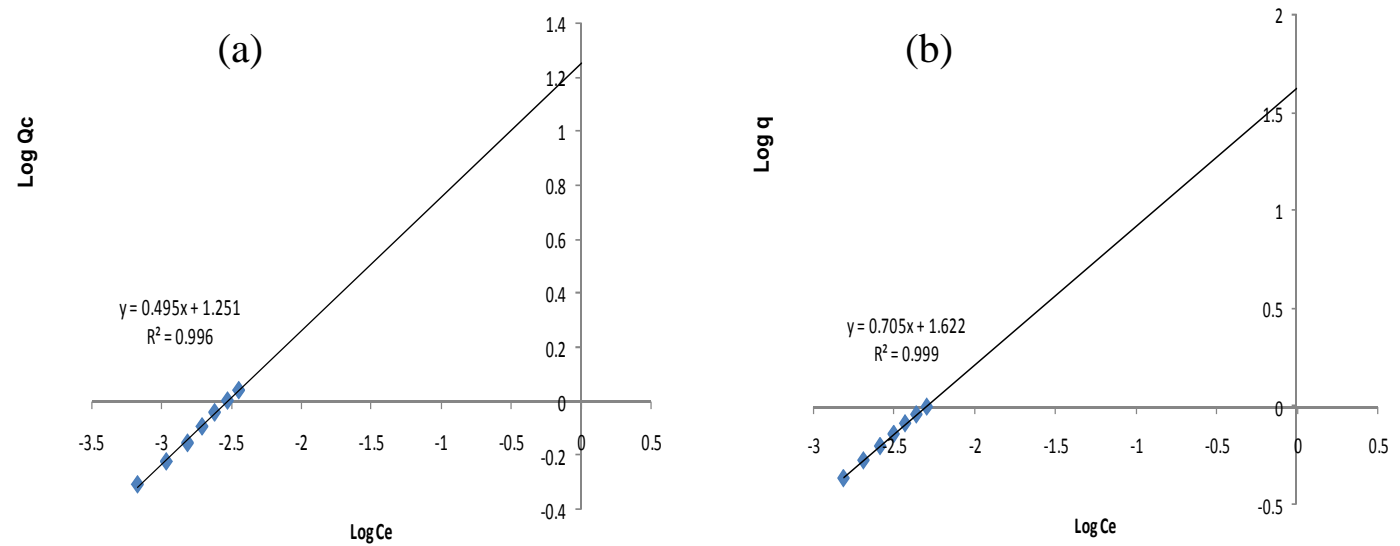

Figure 8: Freundlich Isotherm model with $150 \mu \mathrm{m}$ (a), $300 \mu \mathrm{m}$ (b) acid- treated gypsum. 

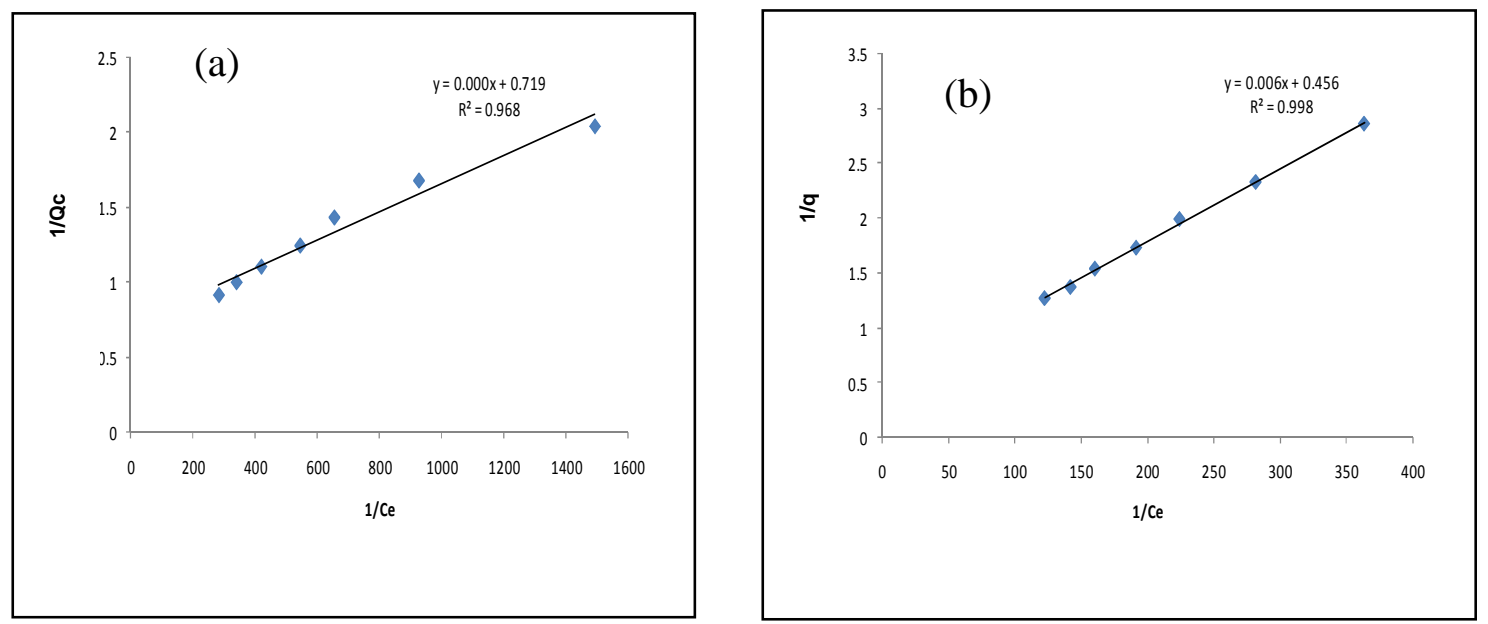

Figure 9: Langmuir Isotherm model with $150 \mu \mathrm{m}$ (a), $300 \mu \mathrm{m}$ (b) acid- treated gypsum.

\section{Conclusion}

From the various studies, gypsum served as an effective adsorbent in the removal of the Reactive Red 1 dye from aqueous solution. Optimal conditions were attained as contact time (25 - 35 mins), $\mathrm{pH}(2)$ and adsorbent dosage of $0.8 \mathrm{~g}$. The smaller particle size $(150 \mu \mathrm{m})$ was a more effective adsorbent attaining a maximum adsorption of $89.8 \%$ in the acid-treated medium. Both Langmuir and Freundlich models fitted well. It is suggested that the rate-controlling step might be a process of chemisorption as kinetically, the adsorption process fitted a pseudo second order.

\section{REFERENCES}

Al-Asheh S, Banat F, Abu-Aitah L. 2003. The removal of methylene blue dye from aqueous solutions using activated and non-activated bentonites. Ads. Science Technology, 21: 451-462.

Alaton IA, Gursoy BH, Schmidt JE. 2008. Advanced oxidation of acid and reactive dyes. Effect of Fenton treatment on aerobic, anoxic and anaerobic processes. Dyes and Pigments, 78: 117-130.

ASTM. 2007. Test method for particle size distribution of granular activated carbon. In Book of Standard. ASTM.
Bakaullah SB, Rauf MA, AIAIi SS. 2007 Removal of Methylene Blue from aqueous solution by adsorption on sand. Dyes and Pigments, 74: 85-87.

Boeningo M. 1994. Carcinogenicity and Metabolism of Azodyes Especially Derived from Benvidine. Gov. Printing DNHS (NIOST-I) publication $\mathrm{N}^{\circ} 66$ : Washington DC, U.S.; 80-119.

Cestari AR, Viera EFS, Mota JA. 2008. The removal of an anionic red dye from aqueous solutions using chitosan beadsThe role of experimental factors on adsorption using a full factorial design. Journal of Hazardous Material, 15: 337343.

Chiou MS, Li HY. 2003. Adsorption behaviour of reactive dye in aqueous on chemical cross-linked beads. Journal of Chemosphere, 50: 1095- 1105.

Cirini G. 2006. Non conventional low cost adsorbents for dye removal A review. Bioresources Technology, 589: 67-75.

Ghoreishi SM, Haghighi R. 2003. Chemical catalytic reaction and biological oxidation for treatment of non-biodegradable textile effluent. Chemical Engineering Journal, 95: $163-169$.

Gong RM, Ding Y, Li M, Yang C, Liu HJ, Sun YZ. 2005. Utilization of powered 
peanut hull as biosorbent for removal of anionic dye from aqueous solution. Dyes and Pigments, 64: 187-192.

Iqbal MJ, Ashiq MN. 2005. Adsorption of Dyes from aqueous solutions on activated charcoal. Journal of Hazardous Materials, 139: 57-66.

Isa HM, Hasnain Lanag LS, Faridah AH, Aziz HA, Ramli AN, Dhas JP. 2007. Low cost removal of disperse dyes from aqueous solution using palm ash. Dyes and Pigments, 74: 446-453.

Inthorn D, Singhto S, Thiravetyan P, Khan E. 2004. Decolourization of basic, direct and reactive dyes by pretreated narrow-leaved cattail (TyphaAngustifolia). Bioresources Technology, 94: 299-306.

Karstens T, Kobs K. 1980. Rhodamine B and Rhodamine 101 as reternce substances for fluorescence quantum yield measurements. Journal of Pluys Chemistry, 84: 1871-1872.

Khraisheh MA, AIg-Houti MS, 2005. Enhanced Dye Adsorption by Microemulsion Modified Calcined Diatomite (stE-CD). Ads.11: 547-549.

Kubin RF, Fletcher AN, 1982. Fluorescence quantum yields of some rhodamine dyes, Journal of Luminescence, 27: 455.

Lehocky M, Mracek A. 2006. Improvement of dye adsorption on synthetic polyester fibers by low temperature plasma pretreatment. Czech Journal of Physics, 56: 1277-1282.

Lqbal MJ, Ashiq MN. 2007. Adsorption of dyes from aqueous solutions on activated charcoal. Journal of Hazardous Material, 139: 57-66.

Martin MJ, Artola A, Dolors Balaguer M, Rigola M. 2003. Activated carbons developed from surplus sewage sludge for the removal of dyes from dilute aqueous solutions. Chemical Engineering Journal, 94: 231- 239.

Nethaji S, Sivasamy A, Thennarasu G, Saravanan S. 2010. Adsorption of malachite green dye onto activated carbon derived from Borassus aethiopum flower biomass. Journal of Hazardous Materials, 181: 271-280.

Ncibi MC, Mahjoub I, Seffen M, Autumn 2007. Adsorptive removal of textile reactive dye using Posidonia oceanica (L.) fibrous biomass. International Journal of Environmental Science Technology, 4: 433-440.

Obunwo CC, Akassawei C. 2011. Adsorptive capacity of Mangifera indica leaf powder in the removal of cobalt ions from aqueous solution. Journal of Chemical Society of Nigeria, 36(1): 1-4.

Ozacar M, Sengil A, 2003. Adsorption of reactive dyes on calcinedalunite from aqueous solutions. Journal of Hazardous Material, 98: 211-224.

Rauf, Muhammad A, Shehadeh I, Ahmed A, Al-Zamly A. 2009. Removal of methylene blue from aqueous solution by using Gypsum as a low cost Adsorbent. World Academy of Science, Engineering and Technology, 55: 608-613.

Suteu D, Zaharia C, Rusu Gabriela. 2010. Reactive dye removal from aqueous solution by sonetion. Cercetari Agronomice in Moldova. 59-65.

Tan IAW, Hameed BH, Ahmad AT. 2007. Equilibrium and kinetic studies on basic dye adsorption by oil palm fibre activated carbon. Chemical Engineering Journal, 127: 11-119. 